\title{
Heat transfer through brick walls for designing the building
} fabric

This paper was downloaded from TechRxiv (https://www.techrxiv.org).

\section{LICENSE}

CC BY 4.0

SUBMISSION DATE / POSTED DATE

$03-11-2021 / 12-11-2021$

\section{CITATION}

Bhardwaj, Abhishek; RATH, MANORANJAN; Pareek, Keshav; AAYUSH, KUMAR (2021): Heat transfer through brick walls for designing the building fabric. TechRxiv. Preprint.

https://doi.org/10.36227/techrxiv.16926439.v1

DOI

10.36227/techrxiv.16926439.v1 


\title{
Heat transfer through brick walls for designing the building fabric
}

\author{
KUMAR AAYUSH \\ KESHAV PAREEK \\ MANORANJAN RATH \\ ABHISHEK BHARDWAJ
}

\begin{abstract}
The main aim of the study is to analyse the heat transfer through the clay brick walls of the residential building to find out the dominant mode of heat transfer and incorporate various materials in the wall to reduce heat loss and increase energy efficiency. The transient thermal analysis was performed using the finite element method, and by employing a CFD program focused on heat transfer processes. Later, two models of building wall fragments incorporating the Phase change materials were developed to identify the optimal position of the PCM layer inside the wall and to investigate the role of $P C M$ on the heat transfer rate. The thermal performance of the Nano Thermal Model (NTM) was tested and the heat-transfer rate was measured using the nanomaterials as nano paints on the walls of the building. Insulation was done with the different types of plywood and finite element simulation was performed to study the change in heat transfer rate. It was observed that conduction and radiation are the important mode of heat transfer and convection can be ignored. The results showed that having the layer of PCM closer to outer wall gives a lowtemperature gain in the indoor state as compared with the PCM layer near the inner wall and rise reported was lowest. Inserting plywood into the sandwich material with Chinese plywood can reduce the heat transfer content. The resulting values can be useful to design the building fabric and reduce the uncertainties in the heat flows. Also, assessing precisely the mode of heat transfers in building configurations is essential, since the calculation of energy requirements through buildings has become of increasing importance lately.
\end{abstract}

Keywords: Heat transfer, clay brick wall, PCM, Nanomaterials, building fabric, efficiency

\section{NOMENCLATURE}

$A, d \quad$ surface area [m2] and layer thickness [m]

$\lambda$ thermal conductivity, heat transfer coefficient due to conduction $[\mathrm{W} /(\mathrm{m} \cdot \mathrm{K})]$

$C p \quad$ specific heat capacity at constant pressure $[\mathrm{MJ} /(\mathrm{kg} \cdot \mathrm{K})]$

$\sigma \quad$ the Stefan-Boltzmann constant, where $\sigma=5.670310-8[\mathrm{~W} /(\mathrm{m} 2 \cdot \mathrm{K} 4)]$

$\rho \quad$ bulk density $[\mathrm{kg} / \mathrm{m} 3]$

$h e, h i \quad$ exterior and interior surface heat transfer coefficients due to combined convection and radiation $[\mathrm{W} / \mathrm{m} 2 \cdot \mathrm{K}]$

$\varepsilon \quad$ thermal-emissivity coefficient [-]

$T$ temperature $[\mathrm{oC}]$

$t, \Delta t \quad$ elapsed time [s] and time step [s]

\section{INTRODUCTION}

The energy usage in buildings for ventilation, heating, and air-conditioning is increasing for the demand of thermal comfort. Energy consumption in public buildings for the comfort of residents has increased drastically over the last decade. To preserve an adequate indoor environment with good thermal comfort for the inhabitants of buildings, the serious issues that concern the thermal properties of building materials should be considered.

There are several ways in which energy efficiency can be increased after properly analysing the thermal behaviour of the walls of a building. Thermal energy storage with phase change material (PCM) have been used at several locations for its role in achieving energy conservation in buildings with thermal comfort. The ability of the PCM materials to absorb, store and release the energy makes it one of the prominent choices for the thermal storage. 
Energy performance can also be increased by integrating the nanomaterials in the building fabrics. This technique of energy consumption by using nanomaterials is useful in a hot and dry climate. The energy consumptions can be reduced by thermally insulating with plywood inserted honeycomb sandwich panels. Different types of plywood can be incorporated between the walls to provide better thermal resistance and increase the thermal efficiency.

In the study conducted by Kanellopoulos et al.,(2017) the thermal behavior of walls corresponding to perforated clay brick masonry layers was performed. Transient thermal analysis was performed to analyse the heat transfer from the inner and outer walls. It was noted that the thermal equations were solved using MATLAB software using the appropriate boundary conditions.

In the study conducted by khan et al.,(2020) the investigation of heat transfer in the presence of PCM material was performed. Several experiments were conducted on heat transfer of a building wall in the presence of PCM material.Two studies were performed by the researchers by placing the PCM layer near the inner wall and near the outer wall and later results were compared.

In the study conducted by Hasan et al.,(2018) the role of PCM in the thermal comfort of a model of a room by incorporating a PCM layer on the ceiling and the walls of the room was studeid. Experimental results demonstrated a reduction in indoor temperature and cooling load.

In the study conducted by Aljenbaz et al.,(2020) Nanomaterials were tested and evaluated on the basis of a matrix which constitutes several factors dependent on environment and socioeconomical criteria.

In the study conducted by Rashwan et al.,(2014) energy performance analysis of integrating building envelopes with nanomaterials was performed. An empirical study was conducted to find out the suitable nano material by comparing several samples of nano material. The selected nanomaterial was incorporated with the paints, coatings and insulating materials and later the results were observed.

In the study conducted by Reengwaree et al.,(2020) the possibility of replacing the plywood-reinforced honeycomb sandwich panel for the conventional honeycomb sandwich panel as building materials was tested. Three types of plywood were handpicked for the study, i.e., Chinese plywood, rubber plywood, and teak plywood, and also the finite element part was performed to study the heat transfer.

In the study conducted by Nazir et al.,(2019) various ways of improving the working of PCM was presented. One of them was using the nanomaterials as additives for improving the thermal storage and conductivity of PCM's.

In the study conducted by Nghana et al.,(2016) the impact of PCM on indoor comfort and energy performance of residential construction in a mild climate was studied. Twin buildings which were tested on their thermal behaviour showed a reduction of temperature fluctuations of the indoor air and wall by $1.4{ }^{\circ} \mathrm{C}$ and 2.7 ${ }^{\circ} \mathrm{C}$, respectively.

\section{METHODOLOGY}

\subsection{Transient Thermal Analysis:}

An important part of an efficient building fabric is the determination of the thermal behaviour of the components that constitute the building envelope. The evolution of a one-dimensional heat wave from one side to another of a homogenous solid layer is shown in Fig. 1. The forcing functions at each side can vary the temperature at every point in the $x$-axis of the structure. The major part of this transient process in the time domain rely on the thermophysical properties and geometrical characteristics of the material layer $(d, \lambda, \rho$ and $C p)$.

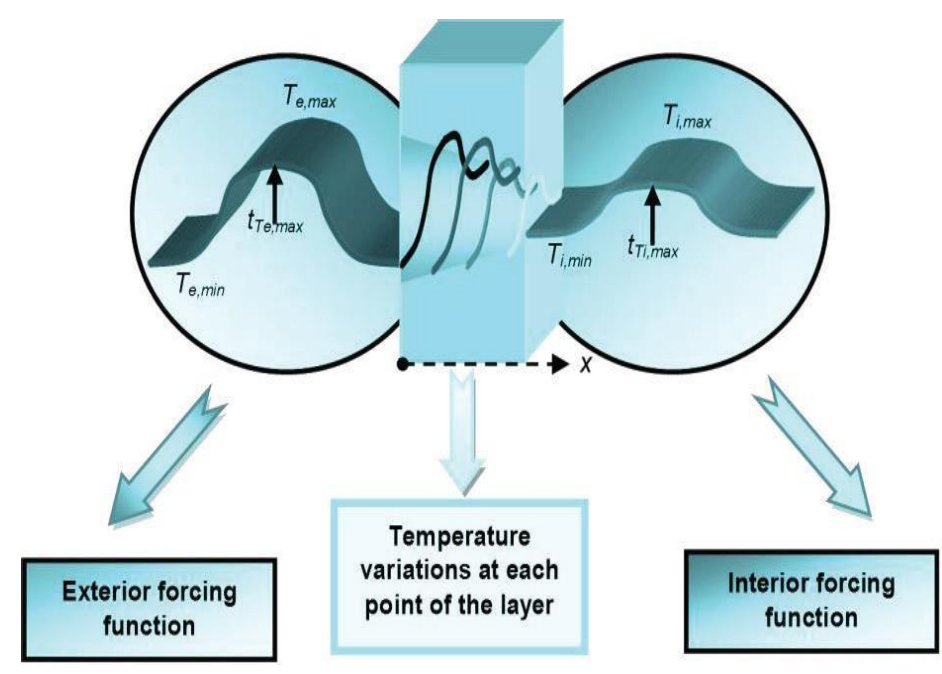

Fig-1: Heat wave evolution of homogenous solid layer along x-axis. (Kanellopoulos et al.,2017)

The heat flow rate in $\mathrm{x}$ - direction due to conduction is given by fourier's law of heat conduction which is defined as:

$\lambda \cdot \frac{\partial^{2} T}{\partial x^{2}}=\rho \cdot C_{p} \cdot \frac{\partial T}{\partial t}$

To solve the equation (1) initial conditions and boundary conditions are required. Steady state at $\mathrm{t}=0$ can be considered as the initial condition. The boundary conditions can be defined by the newton's law and can be given as: 
$-\lambda \cdot \frac{\partial T(0, t)}{\partial x}=h_{e} \cdot\left(T_{e}-T_{s e}\right)$

$-\lambda \cdot \frac{\partial T(d, t)}{\partial x}=h_{i} \cdot\left(T_{s i}-T_{i}\right)$

Where,

he, hi

heat transfer coefficient at the exterior and interior surfaces

Tse $(x=0), T s i(x=\mathrm{d})$ temperatures at the exterior and interior surfaces

$T e, T i$ temperature conditions at the outdoor and indoor environment

In this analysis the brick mortar layers with air cavities are considered. The complexity of the analysis is due the combined heat transfer of all the modes of heat transfer (Kanellopoulos et al.,2017). Individually they can be given as-

- Conductive heat flow in the layers of solid section

- Convective heat flow in the layers with air cavities

- Radiative heat flow between the sides of air cavities

\subsubsection{Geometry and thermophysical properties of the analysed brick layer:}

In general brick-mortar layers provide the better heat absorbing capacity and retain it for the longer time period as compared to the other materials. The thermal behaviour of a non-solid layer depends on the exact geometry and the cross-sectional area of the brick as shown in fig 2 . The geometry of air cavities is taken to be complicated to reduce the effect of the heat flows. The cross section of the layer is show. To find the intensity of radiative heat transfer different emissivity are considered ranging from 0.25 to 1 .

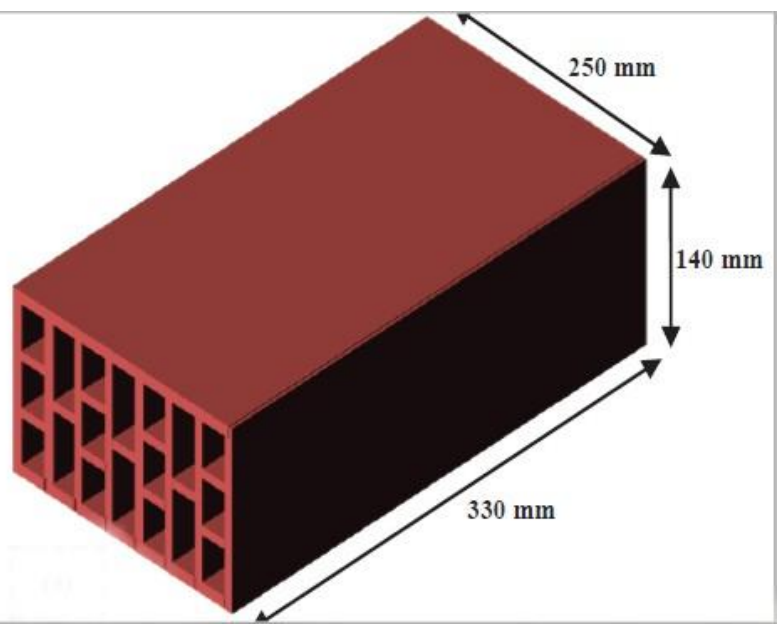

Fig 2: Clay brick for this analysis, (Kanellopoulos et al.,2017)

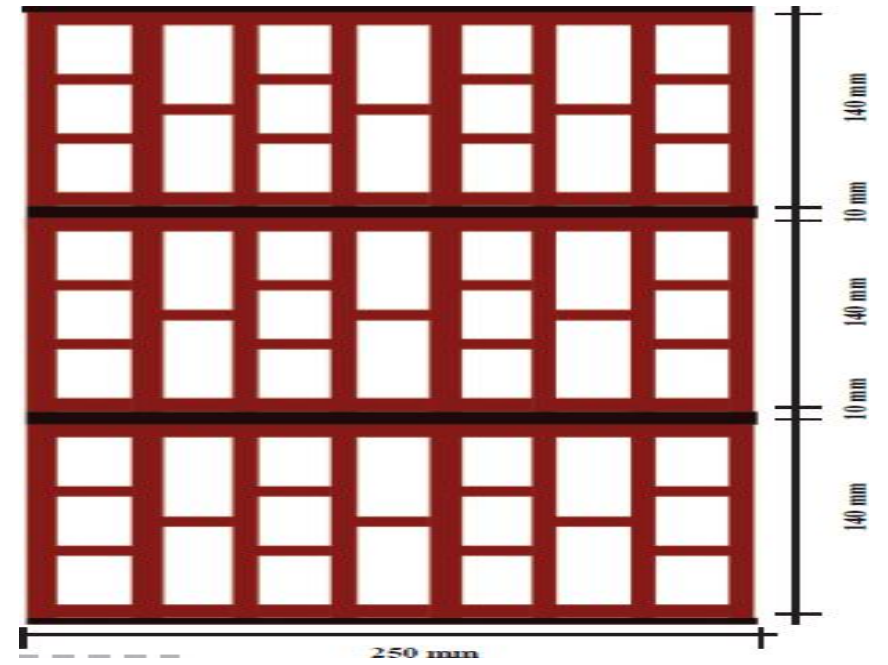

Fig 3: cross section of brick mortar layer, G. (Kanellopoulos et al.,2017)

Table 1. Thermophysical properties of brickwork layer.

\begin{tabular}{llll}
\hline Thermophysical property & Clay brick & Cement motar & Air \\
\hline Thermal conductivity $\lambda[\mathrm{W} /(\mathrm{m} \cdot \mathrm{K})]$ & 0.78 & 1.40 & 0.02551 \\
Bullk density $\rho\left[\mathrm{kg} / \mathrm{m}^{3}\right]$ & 1900 & 1900 & 1.184 \\
Specific heat capacity $C_{p}[\mathrm{~J} /(\mathrm{kg} \cdot \mathrm{K})]$ & 1000 & 1100 & 1007 \\
Thermal-emissivity coefficicent $\varepsilon[-]$ & varying value & 0.89 & - \\
\hline
\end{tabular}

(Kanellopoulos et al.,2017)

\subsection{Analysis of heat transfer in presence of Phase Changing Materials:}

For this experimental study ( Khan et al.,2020) two different models were developed. In first model, the aim was to find out the optimal position of PCM in the brick mortar layer by testing the thermal behaviour of wall with different positions of PCM. In second model, wall integrated PCM, air gap and other materials such as brickbat and sand, one at a time, was tested by comparing the thermal behaviour in each situation.

During the day, the indoor air temperature of space becomes hot as a result of radiation. Once PCM is incorporated with in the building structure, it undergoes a modification of section from solid to liquid by absorbing heat from the inner space. This phase change transition is associated in nursing the endothermal process that absorbs heat. The heat energy is absorbed until the solid is fully liquid. Again, throughout the night as the temperature falls, the PCM solidifies and expels the absorbed heat back to the area. This cycle helps to cut off 
the peaks of cooling masses and heating masses by influencing the surface temperatures.

The thermal mass of the building material also plays an important role in providing the thermal comfort. Low thermal mass can lead to more fluctuation in indoor temperatures. PCM materials helps in increasing the thermal mass and providing thermal comfort by storing and releasing the heat to higher degree. (Barilelo et al.2016)Therefore, the PCM materials should help in two ways. First is to keep the temperature stable inside the rooms. Second is by reducing the thermal peaks on the lower side.

\subsubsection{Experimental setup and procedure:}

Two models of building wall fragments that were constructed are as shown in Fig.4(c). Insulation was done with wood to allow a one-dimensional heat transfer through the constructed wall. One model consists of a heating system and a hot water bath and other model consists of cold-water bath. The hot water is depicted to be the outdoor environment and the other water bath to be the indoor environment. ( Khan et al.,2020)

In Experimental setup 1, there were two segments of brick wall measuring $0.381 \mathrm{~m}$ (length) $\times 0.254 \mathrm{~m}$ (width) $\times 0.152 \mathrm{~m}$ (height $)(15$ inch $\times 10$ inch $\times 6$ inch $)$ and 0.076 $\mathrm{m} \times 0.254 \mathrm{~m} \times 0.152 \mathrm{~m}(3$ inch $\times 10$ inch $\times 6$ inch $)$, a cavity measuring $0.050 \mathrm{~m} \times 0.254 \mathrm{~m} \times 0.152 \mathrm{~m}(2$ inch $\times 10$ inch $\times 6$ inch) to store PCM as shown in fig 4(a).

In Experimental setup 2, there were two segments of plaster each measuring $0.076 \mathrm{~m} \times 0.254 \mathrm{~m} \times 0.114 \mathrm{~m}(3$ inch $\times 10$ inch $\times 4.5$ inch), a segment of stacked bricks measuring $0.114 \mathrm{~m} \times 0.254 \mathrm{~m} \times 0.114 \mathrm{~m}(4.5$ inch $\times 10$ inch $\times 4.5 \mathrm{inch}$ ) and two cavities measuring $0.025 \mathrm{~m} \times 0.254 \mathrm{~m}$ $\times 0.114 \mathrm{~m}(1 \mathrm{inch} \times 10$ inch $\times 4.5 \mathrm{inch})$ to store PCM and water as shown in fig4(b).

Steady-state one-dimensional conduction experiment was run on the models of the building wall fragment. Hot fluid temperature, cold fluid temperature and the temperature of other fragments are measured using the thermocouples at regular intervals of $5 \mathrm{~min}$. Hot fluid water was set at $100^{\circ} \mathrm{C}$, and the cold fluid water was at room temperature. The melting point range of the PCM used in this study is $42{ }^{\circ} \mathrm{C}-72{ }^{\circ} \mathrm{C}$. Paraffin wax type P56-58 supplied by the MERCK is used as phase change material.

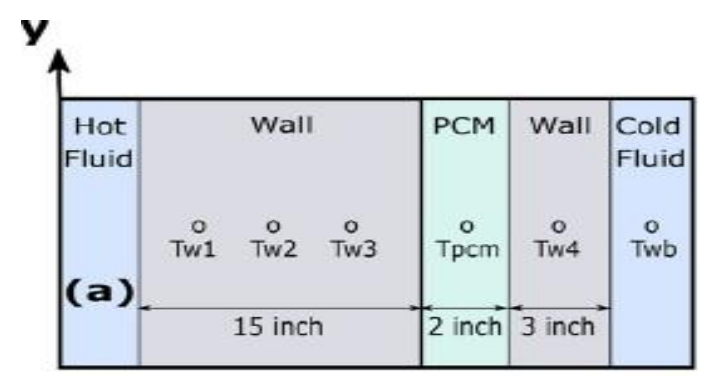

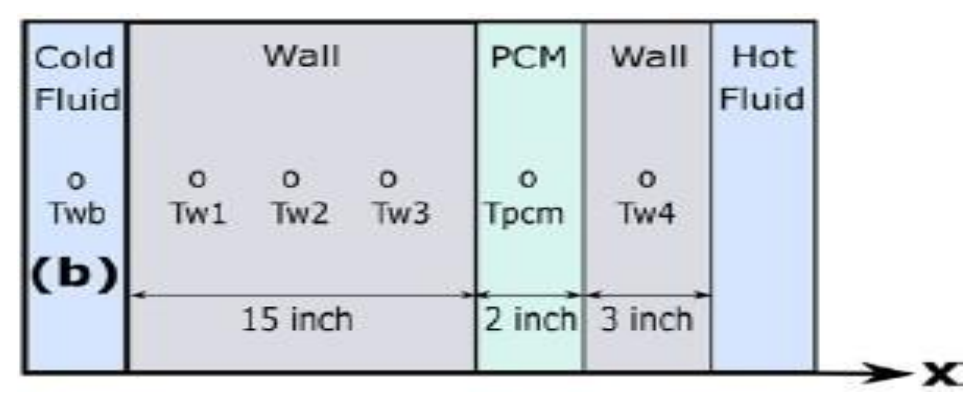

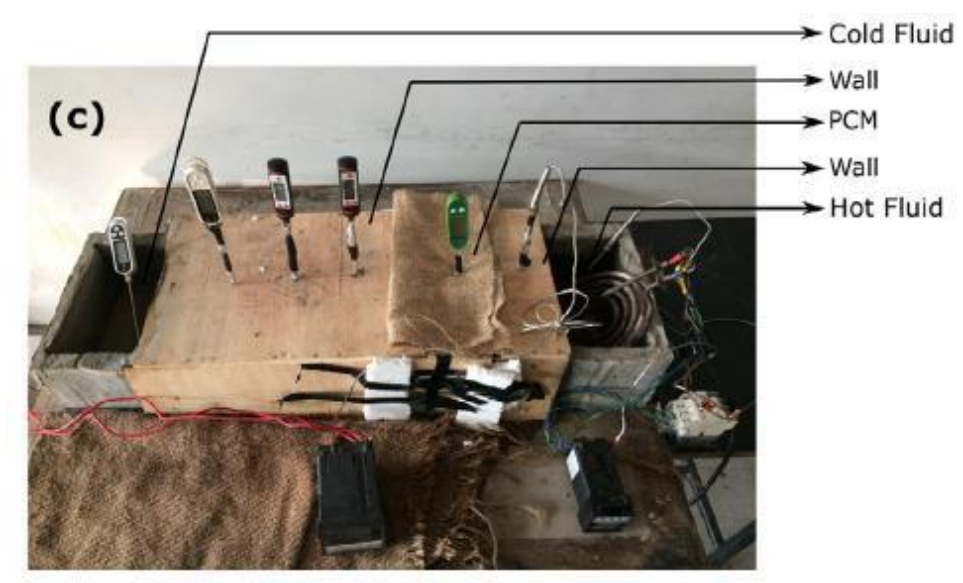

Fig 4: Composition of the building wall fragment (Experimental setup 1); (a) Case 1 - PCM layer 15 inch from the hot fluid, (b) Case 2 - PCM layer 3 inch from the hot fluid, (c) Actual view of Experimental setup 1,( Khan et al.,2020)

Table 2

Thermo physical properties of the different building materials.

\begin{tabular}{llll}
\hline Material & $\begin{array}{l}\text { Density } \\
\left(\mathrm{kg} / \mathrm{m}^{3}\right)\end{array}$ & $\begin{array}{l}\text { Thermal Conductivity } \\
\left(\mathrm{W} \cdot \mathrm{m}^{-1} \cdot \mathrm{K}^{-1}\right)\end{array}$ & $\begin{array}{l}\text { Specific Heat } \\
(\mathrm{J} / \mathrm{kg} \cdot \mathrm{K})\end{array}$ \\
\hline Brickbat & 1700 & 0.7 & 840 \\
Sand & 1600 & 0.25 & 800 \\
Air & 1.225 & 0.026 & 1005 \\
\hline
\end{tabular}

( Khan et al.,2020)

\subsection{Comparison of Nanomaterials with conventional building materials:}

Nanotechnology (Aljenbaz et al.,(2020)) is the technology created by changing the material particles to obtain the different and unique properties. Nanomaterials are the products of nanotechnology which can be used in the building construction line as paints, coatings and thermal insulation and to reduce the harm to environment.

The empirical study (Ahmed et al.,2014) was done at the level of designing the fabric with the use of nanomaterials. This is done by comparing the nano model with the quality model and traditional building materials to research the likelihood of achieving the thermal resistance. Empirical tests were performed through the methods of simulation and by analysing the 
building's energy scenario with advanced software such as Autodesk Ecotect Analysis software. After comparing the several computer-based programmes and because of the facilities Autodesk Ecotect programme was used for the analysis.

\subsubsection{Comparison between the traditional paints and coatings with Nano paints and coatings:}

In this empirical study, the section of the envelope was coated with several layers of traditional, nano paints and coatings and the thermophysical characteristics along with rates of thermal behaviour was compared.

- The Baseline model [A] (traditional building materials).See Fig.5.

(1) The outer layer: traditional paints - cement layer, 30 mm thick.

(2) Brick masonry layer: $250 \mathrm{~mm}$ thick.

(3) The internal layer: traditional paints - cement layer, $30 \mathrm{~mm}$ thick.

\begin{tabular}{|l|l|l|l|l|l|l|}
\hline & Layer Name & Width & Densiky & Sp. Heat & Conduct & Type \\
\hline 1. & Cement Plaster Bulding & 30.0 & 1250.0 & 1080.000 & 0.500 & 85 \\
\hline 2. & Bick. Matonsy Mediom & 250.0 & 2000.0 & 836.800 & 0.711 & 25 \\
\hline 3. & Cement Plaster Bulding & 30.0 & 1250.0 & 1080.000 & 0.500 & 85 \\
\hline
\end{tabular}

\begin{tabular}{|l|l|}
\hline U-Value $(W / m 2 . K)$ & 1.540 \\
\hline Admittance $(W / m 2 . K)$ & 4.340 \\
\hline Solar Absorption $[0-1)$ & 0.1 \\
\hline Visible Transmittance $[0-1)$ & 0 \\
\hline Thermal Decrement $[0-1]$ & 0.22 \\
\hline Thermal Lag (hrs): & 10.57 \\
\hline [SBEM] CM 1: & 0 \\
\hline [SBEM] CM 2 & 0 \\
\hline Thickness (mm) & 310.0 \\
\hline Weight (kg) & 575.000 \\
\hline
\end{tabular}

Fig.5 Thermophysical properties of

baseline(conventional) model. (Ahmed et al.,2014)

- The Nano model (Nano materials). See fig.6

(1) The outer layer: Nano paints layer, $30 \mathrm{~mm}$ thick.

(2) Brick masonry layer: 250 mm thick.

(3) The internal layer: Nano paints layer, $30 \mathrm{~mm}$ thick

\begin{tabular}{|l|l|l|l|l|l|l|}
\hline & Loyer Name & Width & Densily & Sp. Heat & Conduct & Type \\
\hline 1. & Nano Plaster Bulding & 30.0 & 1250.0 & 919.000 & 0.129 & 115 \\
\hline 2. & Brick Mascony Medim & 250.0 & 2000.0 & 836.800 & 0.711 & 25 \\
\hline 3. & Nano Plaster Bulding & 30.0 & 1250.0 & 919.000 & 0.129 & 115 \\
\hline
\end{tabular}

\begin{tabular}{|l|l|}
\hline U-Value (W/m2.K) & 1.010 \\
\hline Admittance (W/m2.K) & 2.690 \\
\hline Solar Absorption (0-1) & 0.418 \\
\hline Visible Transmittance [0-1) & 0 \\
\hline Thermal Deciemenk (0-1) & 0.11 \\
\hline Thermal Lag (hes) & 12.05 \\
\hline [SBEM] CM 1: & 0 \\
\hline [SBEM] CM 2: & 0 \\
\hline Thickness (mm) & 310.0 \\
\hline Weight (kg) & 575.000 \\
\hline
\end{tabular}

Fig.6: Thermophysical properties of nano paints and coatings. (Ahmed et al.,2014)

\subsection{Analysis of heat transfer through walls with thermal insulation with plywood inserted Honeycomb sandwich panel:}

A sandwich material ((Animoy et al.,2015)) is made up of composite materials having two thin but stiff faces at the bottom and top. The sandwich materials increase the durability and strength of the structure. The material is light weight and the faces are capable of the bearing the compressive and tensile stresses.

In this study (Animoy et al.,2015) honeycomb type of sandwich panel was used for the analysis. To properly understand the design and response of honeycomb material finite element method was performed using honeycomb analysis tool. Chinese plywood, rubber plywood, and teak plywood are inserted into the honeycomb sandwich material. The heat transfer ability of the sandwich material of three different insertions were determined by finite element simulations and the one with the best result is used for further study of energy saving efficiency in the building.

\subsubsection{Experimental setup:}

The finite element modelling (Animoy et al.,2015) is designed based on the principle of designing the shape of honeycomb core. The model is $300 \times 300 \times 40 \mathrm{~mm}$. in dimension and is composed of on the two outermost sides the fiberglass panels attached to plywood (either Chinese plywood, rubber plywood, or teak plywood) and polypropylene core. To obtain the accurate experiment result, the model is created in the solid work program and the file is converted to IGES so that it can be opened in the finite element program. The designed model is shown in Fig. 7.

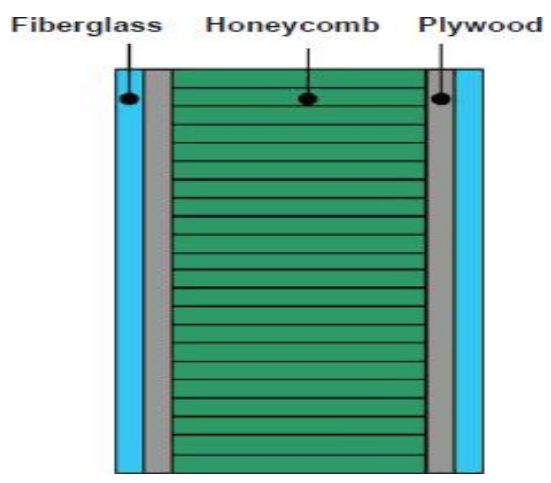

Fig.7: Sandwich material model design, (Animoy et al.,2015)

Two tests were conducted. Initially the honeycomb structure was tested on different temperature ranges to find out their response on thermal resistance. Later the different types of plywood was incorporated and generated results were compared to find out the most optimal plywood for the thermal insulation. 


\subsection{Effect of addition of nanomaterials in PCM's:}

Nanotechnology can be effective in various ways in terms of increasing the thermal storage and thermal conductivity of PCM as discussed by Nazir et al., 2019. Nanosheets, Nanotubes, Nanoparticles etc. when used as additives in PCM can increase the thermal storage of PCM.

The reason behind the increment in thermal storage and thermal conductivity of PCM has been attributed to several reasons. One of them is the Brownian motion of nanoparticles when dispersed in fluids. Brownian motion enables the direct solid-solid heat transfer from one particle to another. Formation of clusters to carry chunks of heat and lattice vibrations are other reasons stated by Nazir et al.,2019 for the increase in thermal conductivity in Phase changing materials.

Carbon was reported to be effective in increasing the thermal storage and conductivity of PCMs. Carbon in form of nanotubes has reported shown an abnormal increasing trend in thermal conductivity of alkanes. The thermal conductivity in the solid phase increased by $250 \%$, while $10 \%$ increment was achieved in the liquid phase with the presence of $0.25 \%$ of carbon.

\section{Results}

Based on the problem statement we found that the thermal analysis of the walls of building is possible. Since, the process is computationally expensive one-dimensional thermal transient analysis was performed. It was found that the dominant mode of heat transfer was conductive in the solid layer and radiative in the air cavities. Convection mode of heat transfer can be precisely ignored.

In case I, the PCM layer was kept at a distance of $0.381 \mathrm{~m}$ from the hot fluid in the $1^{\text {st }}$ experiment setup of analysis of heat transfer in the presence of phase change materials. The PCM did not reach its melting point and was in a solid state due to the high melting point of paraffin. In case 2 , the PCM layer was kept at $0.076 \mathrm{~m}$ from the hot fluid in the $2^{\text {nd }}$ experimental setup of analysis of heat transfer in the presence of phase change materials. Comparison of temperature rise profile of PCM layer for Cases 1 and 2 is shown in Fig.8.

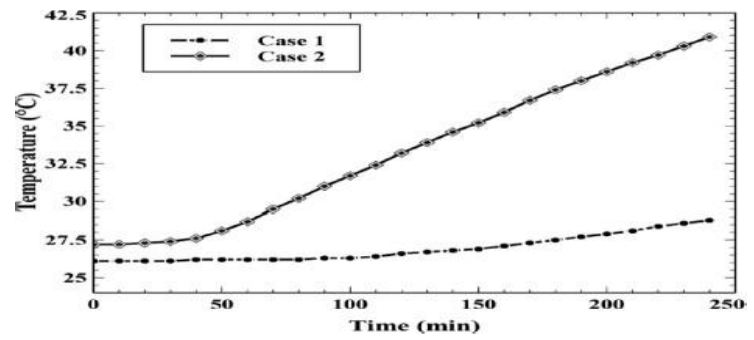

Fig.8: Comparison of temperature rise profile of PCM layer for Cases 1 and 2, (Khan et al.,2020)
In case 1 there is more temperature variation as compared to case 2 as it was placed at a more distance from the hot fluid and when the PCM layer was close to the hot fluid, all the segments that were ahead of the PCM were at steadier temperatures.

Performance of different materials such as Air, Brickbat, Sand etc. were compared with PCM for the case 1 as shown in Fig.

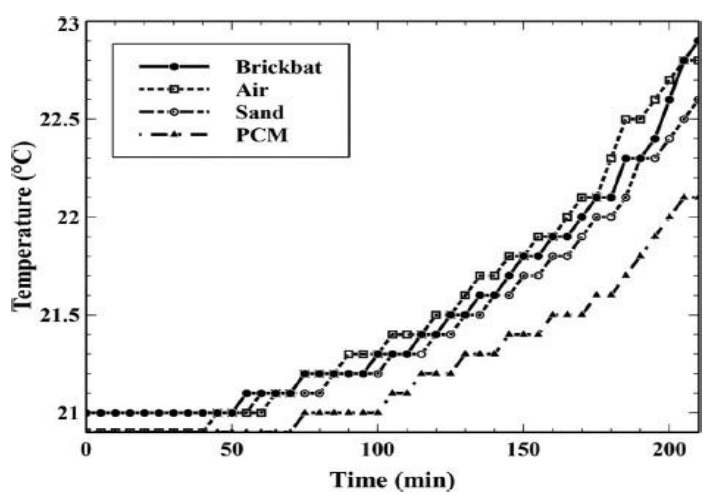

Fig.9: Comparison of the temperature rise profile of the cold-water bath for different building materials, ( Khan et al.,2020)

The performance of Nano paints is better than the traditional or conventional paints in terms of the thermal resistance. They reduce the heat transfer rates upto $40 \%$ through external and internal surfaces and $30 \%$ in case of external surfaces only. This implies that there is good possibility of using nano-paints as an alternative to the traditional paints.

Insulation with Nano-materials can perform better than the convectional nanomaterials in terms of fabric heat transfer. In the study it was found out that U-value of nanomaterials is 8 times less than the U-Value of traditional materials.

In the study of Insulation with plywood inserted honeycomb structure, the result showed that the patterns of heat transfer of honeycomb at temperatures of $50 \mathrm{C}$, $100 \mathrm{C}, 150 \mathrm{C}, 200 \mathrm{C}$, and $250 \mathrm{C}$ are identical. Because of the countless gaps of air in the honeycomb sandwich material, heat transfer caused by the conduction was poor which makes it the material with good insulating property.

The results of thermal properties based on ASTM C 518 in Figs. 10 showed that the Chinese plywood reinforced sandwich material gave a high heat resistance value, indicating that this type of sandwich material provides good insulation, whereas the honeycomb sandwich materials reinforced with teak plywood and rubber plywood respectively ranked second and third in terms of heat resistance. The measurement results were perfectly consistent with the experimental results. 


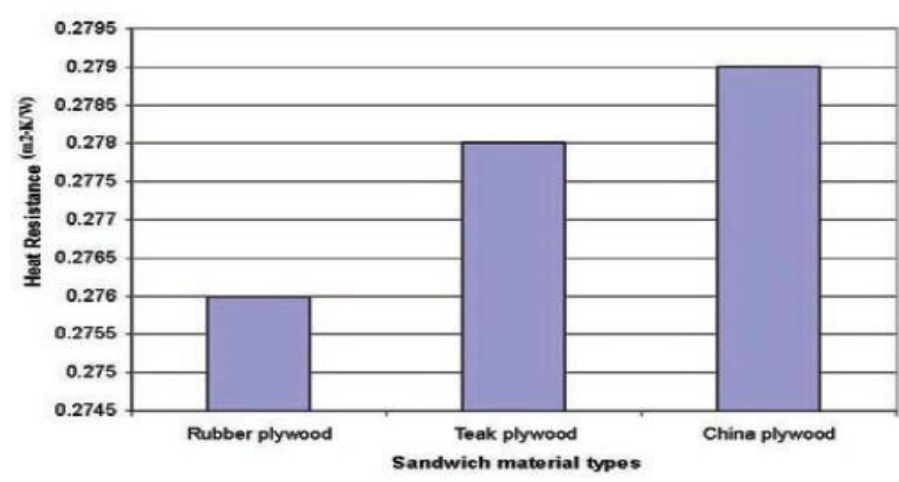

Fig.10: Result of heat resistance measurement based on AMTM C 518 standards, (Animoy et al.,2015)

The time of 2.00-3.00 pm was assumed for the data taken for the analysis because according to the data, maximum amount of electricity was consumed between 2.00-3.00 pm. Electricity up to $1.07 \mathrm{kw}$ was consumed with traditional structures whereas the wall made from the Chinese plywood reinforced sandwich material consumed merely $0.90 \mathrm{kw}$.

\section{Conclusions}

- The dominant mode of heat transfer in the walls are conduction and radiation. Based on the understating of the results, convection can be precisely ignored. As thermal emissivity constant changes with the temperature, the materials with the low and stable range of value should be taken.

- Optimal position of PCM layer in the wall should be near the outer wall. This way we can achieve the steadier temperature of inner area.

- PCM provides the better chance of thermal storage and increase in thermal mass in comparison to other traditional materials such as brickbat, sand etc.

- Using nanomaterials as nano paints and coatings, or in thermal insulations, reduces the thermal conductivity and the U-value (Transmittance Coefficient) which helps in the reduction of energy costs.

- Addition of nanomaterials in PCM leads to better inner comfort by increasing the thermal storage capacity.

- High thermal resistance capacity of Chinese plywood inserted honeycomb material can provide a good opportunity to increase the energy efficiency.

- It can be concluded that the heat resistance can be increased by incorporating the building envelop with several material as stated in the term paper to increase the thermal comfort and energy efficiency.

\section{Acknowledgement}

I would like to take this opportunity to thank our course instructor, Prof. Swarup Kumar for motivating us to explore various research areas and providing us the opportunity to present this term paper. I would also like to thank the Kalinga Institute of Industrial Technology, Digital Library for the ease of access to various research papers.

\section{References}

Ahmad Zeyad Aljenbaz1, Assist. Prof. Dr Çiğdem Çağnan2, 2020, " Evaluation of Nanomaterials for Building Production within the Context of Sustainability", European Journal of Sustainable Development (2020), 9, 1, 53-65.

Mushtaq.1.hasan, Hadi.O.Bashir, 2018,Experimental investigation of phase change materials for insulation of residential buildings", Sustainable and societies.

G. Kanellopoulos, V.G. Koutsomarkosa, K.J. Kontoleon , K. Georgiadis-Filikas., 2017, "Numerical Analysis and Modelling of Heat Transfer Processes through Perforated Clay Brick Masonry Walls", International Conference on Sustainable Synergies from Buildings to the Urban Scale, SBE16.

Rafid Jahangir Khan, Md.ZubayerHossain Bhuiyan, DewanHasan Ahmed, 2020, " Investigation of heat transfer of a building wall in the presence of phase change material (PCM)".

Barilelo Naghna, Fitsum Tariku , 2016, "Phase change material's (PCM) impacts on the energy performance and thermal comfort of buildings in a mild climate", Building and environment.

Hassan Nazir, Mariah Batool, Fransisco J, 2019, “ Recent developments in phase change materials for energy storage applications", International Journal of heat and mass transfer.

Ahmed Rashwan, Osama Farag, Wael Seddik Moustafa, 2014, "Energy performance analysis of integrating building envelopes with nanomaterials", Department of Architecture, Faculty of Engineering, Mansoura University, Mansoura, Egypt.

Amnoiy Reengwaree1*, Varunee Premanond2, Sirichai Torsakul3, 2013,"A Study of Energy Saving in Building through Thermal Insulation with Plywood Inserted Honeycomb Sandwich Panels", 10th Eco-Energy and Materials Science and Engineering (EMSES2012). 